\title{
Major Depression Symptoms in Primary Care and Psychiatric Care Settings: A Cross-Sectional Analysis
}

\author{
Bradley N. Gaynes, MD, MPH \\ A. Jobn Rush, $M D^{2}$ \\ Madbukar H. Trivedi, $M D^{2}$ \\ Stephen R. Wisniewski, $\mathrm{PbD}^{3}$ \\ G. K. Balasubramani, $P b D^{3}$ \\ Donald C. Spencer, MD, MBA ${ }^{1}$ \\ Timotby Petersen, $\mathrm{PbD}^{4}$ \\ Michael Klinkman, $M D^{5}$ \\ Diane Warden, $\mathrm{PbD}^{2}$ \\ Linda Nicholas, $M D, M S^{1}$ \\ Maurizio Fava, MD \\ 'Department of Psychiatry, University \\ of North Carolina School of Medicine, \\ Chapel Hill, NC \\ ${ }^{2}$ Department of Psychiatry, University \\ of Texas Southwestern Medical Center at \\ Dallas, Dallas, Tex \\ ${ }^{3}$ Epidemiology Data Center, Graduate \\ School of Public Health, University of \\ Pittsburgh, Pittsburgh, $\mathrm{Pa}$ \\ ${ }^{4}$ The Depression Clinical and Research \\ Program, Massachusetts General Hospital, \\ Boston, Mass \\ ${ }^{5}$ Department of Family Medicine, Univer- \\ sity of Michigan, Ann Arbor, Mich
}

Conflicts of interest: see end matter.

\section{CORRESPONDING AUTHOR}

Bradley N. Gaynes, MD, MPH

Department of Psychiatry, CB \#7160,

University of North Carolina

School of Medicine

Chapel Hill, NC 27599-7160

bngaynes@med.unc.edu

\begin{abstract}
PURPOSE We undertook a study to confirm and extend preliminary findings that participants with major depressive disorder (MDD) in primary care and specialty care settings have with equivalent degrees of depression severity and an indistinguishable constellation of symptoms.
\end{abstract}

METHODS Baseline data were collected for a distinct validation cohort of 2,541 participants (42\% primary care) from 14 US regional centers comprised of 41 clinic sites (18 primary care, 23 specialty care). Participants met broadly inclusive eligibility criteria requiring a Diagnostic and Statistical Manual of Mental Disorders, Fourth Edition, diagnosis of MDD and a minimum depressive symptom score on the 17-item Hamilton Rating Scale for Depression. The main outcome measures were the 30-item Inventory of Depressive Symptomatology - Clinician Rated and the Psychiatric Diagnostic Screening Questionnaire.

RESULTS Primary care and specialty care participants had identical levels of moderately severe depression and identical distributions of depressive severity scores. Both primary care and specialty care participants showed considerable suicide risk, with specialty care participants even more likely to report prior suicide attempts. Core depressive symptoms or concurrent psychiatric disorders were not substantially different between settings. One half of participants in each setting had an anxiety disorder (48.6\% primary care vs $51.6 \%$ specialty care, $P=.143)$, with social phobia being the most common (25.3\% primary care vs $32.1 \%$ specialty care, $P=.002$ ).

CONCLUSIONS For outpatients with nonpsychotic MDD, depressive symptoms and severity vary little between primary care and specialty care settings. In this large, broadly inclusive uS sample, the risk factors for chronic and recurrent depressive illness were frequently present, highlighting a clear risk for treatment resistance and the need for aggressive management strategies in both settings.

Ann Fam Med 2007;5:126-134. DOI: 10.1370/afm.641.

\section{INTRODUCTION}

$\mathrm{S}$ ince the advent of newer antidepressants during the last 2 decades, primary care physicians have played a greater role in the management of depressive illness. According to data from the National Disease and Therapeutic Index Survey, the proportion of depression-related clinic visits made to primary care clinicians increased from 50\% in 1987 to $64 \%$ in 2001, and depressed patients are more likely to see a primary care physician than a mental health specialist for both diagnosis and treatment. ${ }^{1,2}$ Accordingly, government guidelines about depression treatment in primary care are a key area of public policy, ${ }^{3,4}$ with its import highlighted by the current controversy over the safety of newer antidepressants..$^{5-7}$

Conventional wisdom has held that depressed patients in primary care settings are less severely depressed, ${ }_{1}^{8-10}$ experience a milder course of illness ${ }^{8,11,12}$ have a distinct symptom profile with more complaints of 
fatigue ${ }^{13}$ and somatic symptoms ${ }^{8}$ and are more likely to have accompanying physical complaints ${ }^{8,14,15}$ than depressed patients seeking psychiatric specialty care.

Our earlier report from the Sequenced Treatment Alternatives to Relieve Depression (STAR*D) study (http://www.star-d.org), which was based on the first 1,500 enrolled participants, directly compared participants concurrently enrolled from primary care and specialty care settings and found their levels of depression, distributions of total depressive severity, and symptoms to be remarkably similar. ${ }^{16}$ Some differences did emerge in that report. Specialty care participants were nearly twice as likely to have made a prior suicide attempt, and although nearly one half of participants from each setting endorsed suicidal ideation in the past, it was more common in specialty care patients.

We now report on a subsequent and distinct sample, the remaining 2,541 participants who enrolled in STAR*D from primary care or specialty care settings. Given the broadly inclusive eligibility criteria and limited exclusion criteria (see below), findings should be generalizable to most patients who seek treatment for nonpsychotic major depressive disorder (MDD) in primary care or specialty care settings. In this report we aim to (1) confirm our initial findings regarding baseline sociodemographic and clinical features of primary care and specialty care patients, and (2) extend our findings by reporting on concurrent psychiatric conditions.

\section{METHODS}

\section{Study Description and Organization}

The rationale and design of STAR*D are detailed elsewhere. ${ }^{17,18}$ Briefly, the purpose of STAR*D was to define prospectively which of several treatments are most effective for outpatients with nonpsychotic MDD who have unsatisfactory initial and, if necessary, subsequent clinical treatment outcomes. The STAR*D participants were enrolled at 18 primary care and 23 specialty care settings across the United States, with advertising for symptomatic volunteers being proscribed. Both primary care and specialty care sites that provided care to public and private sector patients were selected on the basis of having (1) sufficient patient numbers, (2) sufficient numbers of clinicians, (3) sufficient administrative support, and (4) sufficient numbers of racial/ethnic minority patients so that the study population could mirror the US Census and results would be widely generalizable. The median number of clinicians at the 18 primary care sites was 14.5 compared with 12.0 at the 23 primary care sites. Three quarters of the facilities were privately owned, and approximately two thirds were freestanding (ie, not hospital-based).

The institutional review boards at the National
Coordinating Center (Dallas), the Data Coordinating Center (Pittsburgh), and at each of 14 US regional centers (each of which oversaw the study at 2 to 4 clinical sites) approved the study protocol.

\section{Study Population}

Broadly inclusive selection criteria, described in detail elsewhere, ${ }^{17,18}$ were used to optimize generalizability of findings to patients already being seen in outpatient settings. Briefly, established outpatients, in either primary care or specialty care settings and identified by their clinician as having a depression requiring treatment, were asked to participate in STAR*D. All risks, benefits, and adverse events associated with the trial were explained to potential participants, who provided written informed consent before study participation. Eligible participants were aged 18 to 75 years, met Diagnostic and Statistical Manual of Mental Disorders, Fourth Edition (DSM-IV) criteria for single or recurrent nonpsychotic MDD, scored $\geq 14$ (moderate severity) on the 17 -item version of the Hamilton Rating Scale for Depression $(\text { HRSD17 })^{19,20}$ as rated by the clinical research coordinator, and were not resistant to an adequate antidepressant treatment trial during the current episode. Exclusion criteria included psychiatric illness requiring a different treatment approach (eg, bipolar disorder or psychotic symptoms), or a seizure disorder or other general medical condition that contraindicated medications used in the first 2 protocol treatment steps. All other psychiatric and medical comorbidities were allowed.

\section{Measurements}

At baseline, the clinical research coordinators collected standard demographic information, selfreported psychiatric history, and current general medical conditions as evaluated by the Cumulative Illness Rating Scale (CIRS). ${ }^{21}$

Participants also completed the Psychiatric Diagnostic Screening Questionnaire (PDSQ), ${ }^{22,23}$ which consists of 126 yes/no items to assess symptoms of the 13 various nonpsychotic DSM-IV disorders. Based on prior reports, ${ }^{22}$ we selected a scoring procedure and thresholds that yielded a $90 \%$ specificity in relation to the reference standard diagnosis rendered by a structured interview (the Structured Clinical Interview for DSM-IV, or SCID). ${ }^{24}$

The research outcomes assessor used a telephone interview $^{25}$ at baseline to collect responses for the HRSD17 and the 30-item Inventory of Depressive Symptomatology (IDS-C30), ${ }^{26,27}$ a validated instrument that uses unconfounded items to measure both core criterion diagnostic symptoms and associated symptoms. Because the results of these 2 were identical, we only report the latter. 
The Interactive Voice Response system ${ }^{28}$ was used to collect responses for health perceptions (the 12-Item Health Survey, or SF-1229), quality of life measures (Quality of Life Enjoyment and Satisfaction Questionnaire $^{30}$ ), and the Work and Social Adjustment Scale (WSAS). ${ }^{31}$

\section{Data Analysis}

We compared continuous measures by setting using the appropriate parametric or nonparametric test. Using a $\chi^{2}$ test, we compared discrete variables across setting. We used multiple logistic regression models for dichotomous variables or analysis of covariance models for continuous variables to adjust the analyses for any demographic differences identified, length of the current episode, and number of general medical comorbidities (CIRS total score). $P$ values $\leq .05$ were considered significant in the above analyses. We performed no adjustments of $P$ values for multiple comparisons, so results must be interpreted accordingly.

\section{RESULTS}

\section{General}

We report on the final 2,541 participants enrolled in STAR*D, which represented $92 \%$ of the 2,755 screened
Overall, 41.8\% ( $\mathrm{n}=1,063)$ of enrolled participants came from primary care settings, whereas $58.2 \%(n=1,478)$ came from specialty care settings. Compared with the prior sample, a larger proportion of the current sample was enrolled from primary care settings ( $42 \%$ of the current sample vs $34 \%$ of the prior sample $P<.001)$.

\section{Sociodemographic and Clinical Features}

The overall levels of depressive symptom severity for primary care and specialty care participants were similar (IDS-C30: 35.2 in primary care and 35.4 in specialty care), and they reflect a moderate-to-severe level of depressive symptoms. Furthermore, the distribution of total IDS-C30 scores did not differ between the 2 settings (Figure 1). Sociodemographic differences are displayed in Table 1. Of note, primary care participants in this sample were more than twice as likely to be Hispanic.

\section{Course of Illness and Suicidal Risk}

Primary care participants were older than specialty care participants at the onset of their first depressive episode (median of 25 years primary care vs 19 years specialty care) and were less likely to have MDD begin before the age of 18 years $(33.7 \%$ vs $47.2 \% ; P<.001)$. Primary care participants reported a comparatively

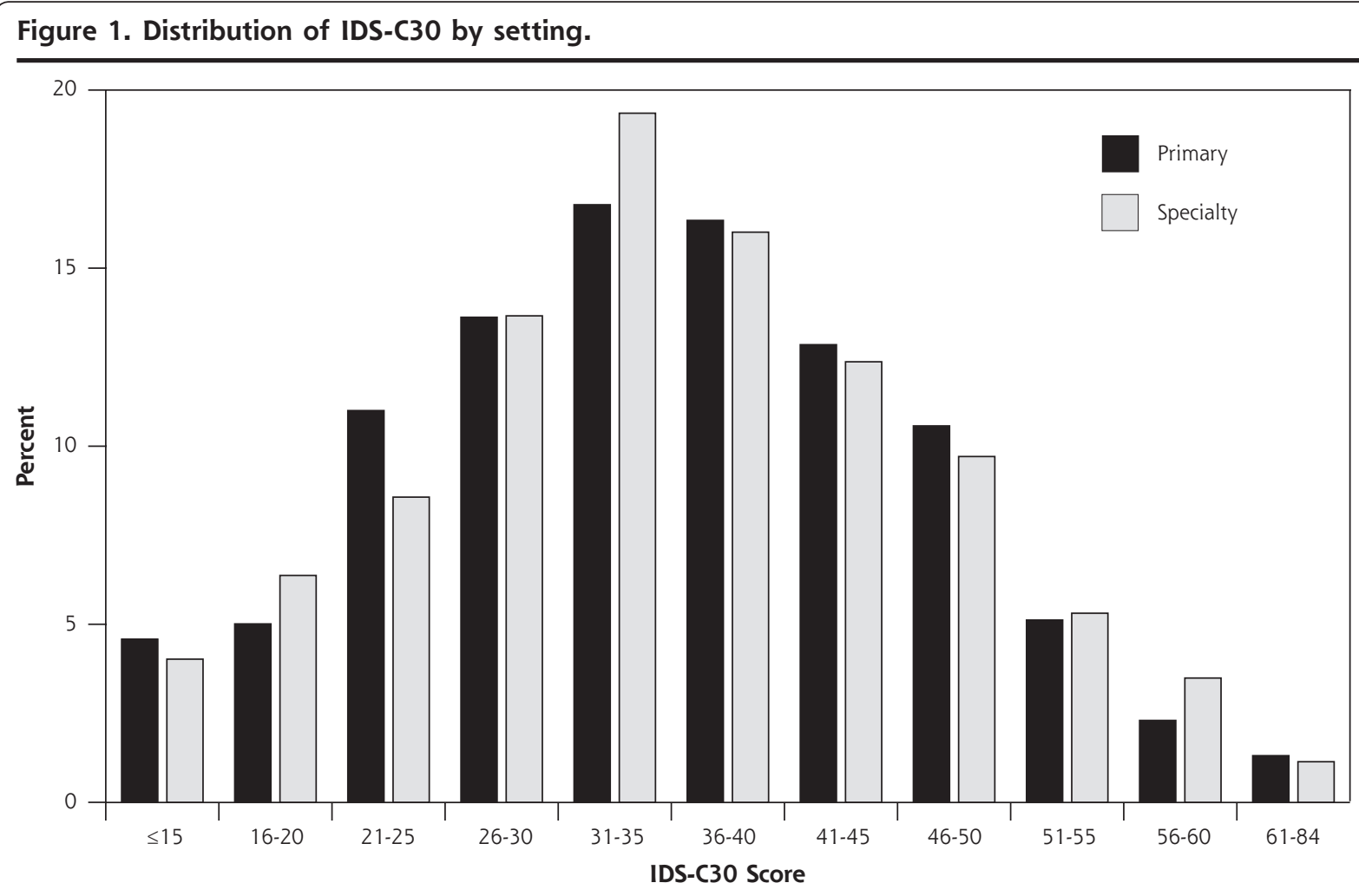

IDS-C30 = 30-item Inventory of Depressive Symptomatology. 
longer duration of their current major depressive episode (median of 10 months vs 6 months; $P<.001$ ). There was no difference in the length of illness (time from first major depressive episode to study entry).

Specialty care participants reported a greater likelihood of a history of attempted suicide than did primary care participants $(18.1 \%$ vs $13.1 \% ; P=<.001)$. Slightly more specialty care participants than primary care participants endorsed suicidal ideation in the previous week (ie, had thoughts within the week that life was not worth living: $51.4 \%$ vs $42.8 \%$; adjusted $P$ $<.001$ by IDS-C30). There was no difference between the proportions reporting a family history of suicide (2.7\% of participants in each setting).

\section{Current General Medical Conditions and Quality of Life}

Compared with specialty care participants, primary care participants reported a greater total CIRS score (5.1 vs 3.9; $P<.001$; Table 2). The most common comorbidities as indicated by a CIRS score $\geq 2$ (indicating at least moderate disability) were musculoskeletal, including pain $(24 \%$ primary care vs $14 \%$; specialty care $P<.001)$; vascular, including hypertension (23\% primary care vs $12 \%$ specialty care $\left.{ }_{i}<.001\right)$; endocrine/metabolic and breast, including diabetes (19\% primary care vs $9 \%$ specialty care $P<.001)_{i}$ and upper gastrointestinal $(15 \%$ primary care vs $9 \%$ specialty care $P<.001)$. Other quality-of-life measures, while significant, showed only slight differences.

\section{Depressive Symptoms}

We compared the individual items on the IDS-C30 for the 2 groups and adjusted by demographic differences, length of current depressive episode, and general medical condition total score. We calculated the proportion of participants in each group for whom the symptom was present (ie, rated $\geq 1$ ) (this information is displayed in the Supplemental Table at http://www.annfammed. org/cgi/content/full/5/2/126/DC1). We found borderline significant but largely clinically unimportant differences in symptom items of the essential mood

Table 1. Baseline Characteristics by Setting: Clinical Severity and Sociodemographic Features, by Recruitment Setting

\begin{tabular}{|c|c|c|c|c|}
\hline $\begin{array}{l}\text { Baseline } \\
\text { Characteristics }\end{array}$ & $\begin{array}{c}\text { Primary Care } \\
\mathrm{n}=1,063(41.8 \%) \\
\text { Mean (SD) }\end{array}$ & $\begin{array}{c}\text { Specialty Care } \\
\mathrm{n}=1,478(58.2 \%) \\
\text { Mean (SD) }\end{array}$ & $\begin{array}{c}\text { Total } \\
\mathrm{N}=2,541 \\
\text { Mean (SD) }\end{array}$ & $P$ Value \\
\hline HRSD17 (ROA) & $19.6(6.5)$ & $19.7(6.4)$ & $19.6(6.5)$ & .839 \\
\hline IDS-C30 (ROA) & $35.2(11.6)$ & $35.4(11.3)$ & $35.3(11.4)$ & .699 \\
\hline Age, years & $43.7(13.3)$ & $38.2(13.0)$ & $40.5(13.4)$ & $<.001$ \\
\hline Years of schooling & $12.8(3.5)$ & $13.8(2.9)$ & $13.4(3.2)$ & $<.001$ \\
\hline Race, \% & & & & .866 \\
\hline White & 73.9 & 74.6 & 74.3 & \\
\hline Black or African American & 17.6 & 16.8 & 17.1 & \\
\hline Others & 8.5 & 8.6 & 8.6 & \\
\hline Ethnicity, Hispanic, \% & 22.0 & 9.3 & 14.6 & $<.001$ \\
\hline Sex, female, \% & 68.0 & 59.0 & 62.8 & $<.001$ \\
\hline Marital Status, \% & & & & $<.001$ \\
\hline Never married & 25.3 & 34.6 & 30.7 & \\
\hline Married & 42.9 & 39.4 & 40.8 & \\
\hline Divorced & 26.1 & 24.2 & 25.0 & \\
\hline Widowed & 5.7 & 1.8 & 3.5 & \\
\hline Employment status, \% & & & & .029 \\
\hline Unemployed & 38.0 & 38.3 & 38.2 & \\
\hline Employed & 55.1 & 57.2 & 56.3 & \\
\hline Retired & 6.9 & 4.4 & 5.5 & \\
\hline Insurance Status, \% & & & & $<.001$ \\
\hline Private insurance & 44.2 & 52.3 & 48.9 & \\
\hline Public insurance* & 22.1 & 8.4 & 15.5 & \\
\hline No insurance & 30.7 & 39.3 & 35.6 & \\
\hline Level of education, \% & & & & $<.001$ \\
\hline Less than completed college & 80.1 & 72.6 & 75.7 & \\
\hline Completed college or more & 19.9 & 27.4 & 24.3 & \\
\hline
\end{tabular}


components: primary care participants tended to be less likely to complain of depressed mood (96.6\% vs $97.6 \%$; $P=.053)$ and were slightly less likely to have anhedonia $(80.6 \%$ vs $85.7 \% ; P=.002)$.

There were no significant differences between the likelihood of having the core criterion symptoms of appetite or weight change, sleep disturbance, psychomotor slowing, loss of energy, or feeling worthless. As noted previously, specialty care participants were significantly more likely to endorse suicidal ideation. Two other core symptoms showed a slight but significant difference between the 2 settings: depressed specialty care participants were slightly more likely to endorse psychomotor agitation $(64.5 \%$ vs $60.7 \% ; P=.019)$ and decreased concentration $(82.5 \%$ vs $76.6 \% ; P=.008)$.

\section{Psychiatric Comorbidities}

It was common in both settings for participants to have at least 1 comorbid psychiatric illness (Table 3 ), but it was slightly less common in primary care settings (59.2\% vs $64.1 \%$; adjusted odds ratio (AOR), $1.31 ; P=$ .003). Approximately one half of participants in each

Table 2. Current General Medical Conditions and Function/Quality of Life, by Recruitment Setting

\begin{tabular}{|c|c|c|c|c|c|c|c|}
\hline \multirow[b]{2}{*}{$\begin{array}{l}\text { Baseline } \\
\text { Characteristics }\end{array}$} & \multicolumn{2}{|c|}{$\begin{array}{c}\text { Primary Care } \\
\mathrm{n}=1,063(41.8 \%)\end{array}$} & \multicolumn{2}{|c|}{$\begin{array}{c}\text { Specialty Care } \\
\mathbf{n}=1,478(58.2 \%)\end{array}$} & \multirow{2}{*}{$\begin{array}{c}\text { Total } \\
\mathrm{N}=2,541 \\
\text { Mean (SD) }\end{array}$} & \multirow[b]{2}{*}{$\begin{array}{l}\text { Unadjusted } \\
P \text { Value }\end{array}$} & \multirow[b]{2}{*}{$\begin{array}{l}\text { Adjusted } \\
P \text { Value* }\end{array}$} \\
\hline & Mean (SD) & $\begin{array}{l}\text { Adjusted } \\
\text { Mean (SE) }\end{array}$ & Mean (SD) & $\begin{array}{l}\text { Adjusted } \\
\text { Mean (SE) }\end{array}$ & & & \\
\hline CIRS, total score & $5.1(4.1)$ & - & $3.9(3.7)$ & - & $4.4(3.9)$ & $<.001$ & - \\
\hline \multicolumn{8}{|l|}{ SF-12 } \\
\hline Physical & $46.4(12.3)$ & $47.6(0.5)$ & $51.1(11.6)$ & $49.5(0.5)$ & $49.2(12.1)$ & $<.001$ & .004 \\
\hline Mental & $28.9(9.8)$ & $28.7(0.4)$ & $25.5(8.3)$ & $26.2(0.4)$ & $26.9(8.8)$ & $<.001$ & $<.001$ \\
\hline WSAS & $22.3(9.8)$ & $21.8(0.5)$ & $24.4(8.9)$ & $24.2(0.4)$ & $23.5(9.3)$ & $<.001$ & $<.001$ \\
\hline Q-LES-Q & 42.7 (15.9) & $44.0(0.7)$ & $41.0(14.9)$ & $41.2(0.7)$ & $41.7(15.4)$ & 0.013 & $<.001$ \\
\hline
\end{tabular}

Table 3. Association of Primary/Specialty Setting With Psychiatric Comorbidities

\begin{tabular}{|c|c|c|c|c|c|c|}
\hline \multirow{2}{*}{$\begin{array}{l}\text { Type and No. of Psychiatric } \\
\text { Comorbidity }\end{array}$} & \multirow{2}{*}{$\begin{array}{c}\text { Primary Care } \\
n=1,063 \\
(41.8 \%) \%\end{array}$} & \multirow{2}{*}{$\begin{array}{c}\text { Specialty Care } \\
n=1,478 \\
(58.2 \%) \%\end{array}$} & \multicolumn{2}{|c|}{ Unadjusted } & \multicolumn{2}{|c|}{ Adjusted* } \\
\hline & & & OR & $P$ Value & OR & $P$ Value \\
\hline \multicolumn{7}{|l|}{ Type of psychiatric comorbidity } \\
\hline Anxiety disorders & 48.6 & 51.6 & 1.06 & .143 & 1.23 & .019 \\
\hline Social phobia & 25.3 & 32.1 & 1.39 & .001 & 1.37 & .002 \\
\hline Generalized anxiety disorder & 2.3 & 21.2 & 1.05 & .604 & 1.26 & .037 \\
\hline Posttraumatic stress disorder & 16.5 & 17.6 & 1.08 & .494 & 1.26 & .054 \\
\hline Obsessive compulsive disorder & 15.1 & 13.4 & 0.87 & .228 & 0.96 & .755 \\
\hline Panic & 14.5 & 11.1 & 0.74 & .012 & 0.88 & .333 \\
\hline Agoraphobia & 12.2 & 11.7 & 0.96 & .729 & 1.33 & .046 \\
\hline Nonanxiety disorders & 29.3 & 33.0 & 1.13 & .051 & 1.21 & .043 \\
\hline Alcohol abuse & 1.4 & 13.1 & 1.30 & .044 & 1.21 & .411 \\
\hline Drug abuse & 6.0 & 9.1 & 1.57 & .005 & 1.22 & .245 \\
\hline Somatoform & 3.0 & 1.8 & 0.59 & .05 & 0.98 & .947 \\
\hline Hypochondriasis & 6.1 & 3.3 & 0.52 & .001 & 0.79 & .285 \\
\hline Bulimia & 1.8 & 13.4 & 1.27 & .056 & 1.36 & .025 \\
\hline \multirow[t]{2}{*}{ Prevalence of any psychiatric comorbidity } & 59.2 & 64.1 & 1.23 & .014 & 1.31 & .003 \\
\hline & No. & No. & \multicolumn{2}{|c|}{$\begin{array}{l}\text { Unadjusted } \\
P \text { Value }\end{array}$} & \multicolumn{2}{|c|}{$\begin{array}{l}\text { Adjusted* } \\
P \text { Value }\end{array}$} \\
\hline \multicolumn{7}{|l|}{ No. of psychiatric comorbidities } \\
\hline Mean & 1.4 & 1.5 & \multicolumn{2}{|c|}{.041} & \multicolumn{2}{|c|}{.002} \\
\hline Median & 1.0 & 1.0 & \multicolumn{2}{|c|}{ ns } & \multicolumn{2}{|r|}{ ns } \\
\hline
\end{tabular}


setting had an anxiety disorder $(48.6 \%$ in primary care vs $51.6 \%$ in specialty care; $\mathrm{AOR}, 1.23, P=.019)$, while approximately one third in each setting had a disorder other than an anxiety disorder $(29.3 \%$ in primary care, $33.0 \%$ in specialty care $\left.\mathrm{AOR}_{1} 1.21_{i} \mathrm{P}=.043\right)$. The average number of comorbidities was similar between settings.

In each setting, the most common single comorbidity was social phobia, which was less likely in primary care settings $(25.3 \%$ vs $32.1 \%$; AOR, 1.37 ; $=.002)$. The remaining anxiety comorbidities showed less difference, with generalized anxiety disorder slightly more common in specialty care settings and agoraphobia slightly more common in primary care settings. Of the non-anxiety-disorder comorbidities, bulimia was the only one for which the likelihood of comorbidity differed by setting; it was more common in specialty care settings $(13.4 \%$ vs $10.8 \% ; A O R, 1.36 ; P=.025)$.

\section{DISCUSSION}

These results, which represent the largest direct comparison of depressed primary care and specialty care patients ever conducted, strongly confirm the findings from our initial, separate cohort analysis. Among the final 2,541 participants enrolled in STAR*D, those from primary care and specialty care settings with nonpsychotic MDD had equivalent degrees of depressive severity and an identical distribution of total depression severity scores. The moderate degree and range of depressive severity we found is consistent with the level seen in previous primary care clinical trials with more restrictive eligibility criteria. ${ }^{32-34}$ In addition, the specific depressive symptoms did not appear to differ substantially between the 2 settings. These findings further challenge the conventional wisdom that primary care patients with major depressive illness requiring treatment are less depressed. Our findings are consistent with our earlier STAR*D findings of equivalent depressive symptoms and confirm a consistent trend across a broad range of sites. Our initial results were neither chance findings nor a selection bias reflecting a study in start-up mode. Such confirmation is important given the risk of contradictory and initially stronger effects seen in clinical research. ${ }^{35,36}$

Furthermore, these results are generalizable to the real-world practice setting in the United States for patients identified as needing treatment of MDD and who agree to antidepressant medication. The characteristics of the patient population (predominantly white, female, employed, married, and privately insured, with approximately one fifth receiving public insurance) correspond to those reported for adult outpatients being seen for depression in the United States in the nationally representative samples assessed in the National Ambulatory Medical Care Survey ${ }^{37}$ and the National Medical Expenditure Survey. ${ }^{38}$ The frequent medical and psychiatric comorbidities similarly make this population more representative of depressed patients seen for care. ${ }^{39-41}$

The specific depressive symptoms in each setting were essentially equivalent. Although primary care participants were slightly less likely report anhedonia, this difference is of questionable clinical importance, given that $97 \%$ from each setting had depressed mood, the other essential feature. Also, only 2 core symptoms - psychomotor agitation and decreased concentration — showed a slight but significantly greater likelihood in specialty care settings. These findings suggest substantial similarity between symptomatic depressive patients and reinforce our earlier findings.

As with earlier studies making a comparison between the 2 settings from an epidemiological $1^{10,42}$ and a managed care ${ }^{42}$ perspective, depressed primary care patients were slightly older, had fewer years of schooling, were more likely to be African American, were more likely to be female, and were less likely to be employed. Our findings reproduce and extend these reported sociodemographic differences to a greater variety of clinical settings.

Our results also confirm and underscore that risk factors for suicidality, such as prior attempts and recent suicidal ideation, ${ }^{43}$ are common in both primary care and specialty care settings, although significantly more likely in specialty care settings. In addition, our results confirm that patients in specialty care clinics were more likely to have their first depressive illness before the age of 18 years. Both suicidality and chronicity, then, appear as key variables increasing the likelihood of accessing psychiatric clinics for depression management.

Our findings extend the similarity of depressive symptoms to include psychiatric comorbidity. Well more than one half of depressed participants in each setting had a comorbid psychiatric illness, usually an anxiety disorder, which was slightly more common in a specialty care setting. The $50 \%$ rate of comorbid anxiety disorders is consistent with reports from community settings ${ }_{r}{ }^{44}$ psychiatric outpatient clinics, ${ }^{45,46}$ and primary care populations. ${ }^{47,48}$ This high rate of psychiatric comorbidity in each setting is important because psychiatric comorbidity is a strong predictor of persistent and recurrent depression. ${ }^{47,49}$

This study has a number of limitations. First, STAR*D clinics were not based on a random sampling of primary care and specialty care clinics in the United States; clinical sites were selected based on the availability of patients, clinicians, and administrative support. Still, the racial and ethnic composition 
approximates US Census (2000 US Census), which enhances its likelihood of being generalizable.

Second, the PDSQ is a screening instrument, rather than a reference standard diagnostic instrument, and it has not been validated in primary care settings. Although we set parameters to yield $90 \%$ specificity relative to a reference standard, our estimates could be biased toward either over- or underreporting. Indeed, our findings may underreport psychiatric comorbidity. While broadly inclusive, our selection criteria excluded patients with psychotic symptoms and a primary diagnosis of obsessive-compulsive disorder or eating disorders. Still our main findings regarding the similar rates of comorbid anxiety disorders are likely accurate the PDSQ has shown excellent test characteristics as a screen for anxiety disorders comorbid with major depression relative to the reference standard SCID, ${ }^{50,51}$ and as noted earlier, the rates of comorbid anxiety disorders are consistent with earlier published reports.

Third, these findings do not apply to those clinic patients who are not identified as depressed, a welldescribed group who may represent as much as $50 \%$ of those depressed in primary care settings. ${ }^{52-55}$ Rather, our results apply to those populations of primary care and specialty care settings who are identified as being depressed. This group remains at marked risk of not receiving adequate treatment regardless of treatment location. In a nationally representative sample of the US population, Kessler et al found that of those identified as needing treatment for depression, only $40 \%$ receive minimally adequate treatment, with deficiencies noted in both primary care and specialty care settings. ${ }^{56}$ Similarly, in a nationally representative sample of adults initiating a new episode of antidepressant treatment for depression, Olfson et al found that a substantial proportion of the patients discontinued antidepressant therapy during the first 30 days (42.4\%). ${ }^{57}$

Finally, these data are hypothesis generating in nature. We conducted multiple statistical comparisons without Bonferroni correction for multiple tests, which increases the likelihood of finding chance associations. Our findings identified very few such associations, however, and most of those identified were of questionable clinical importance. For example, the site differences found with our health-related quality-oflife measures (SF-12 and WSAS) fell somewhat short of either the approximately one half a standard deviation $^{58}$ or standard error of measurement ${ }^{59}$ thresholds that have been suggested as a clinically meaningful "minimally important difference." We hope these results serve to stimulate further research that directly compares depressive illness in primary care and psychiatric outpatient sites.
The similarity in symptoms between the 2 settings has a number of implications. First, it suggests that, given similar populations to begin with, clinical trial results from primary care and specialty care may be equivalent, and results may be more generalizable between settings. Indeed, the initial outcomes report from STAR*D reported no difference by setting. ${ }^{60}$ Whether these outcomes differ by setting for resistant depressions with subsequent treatments will be reported. Second, the similarity of symptoms may reflect the reality of US contemporary primary care practice. As community mental health clinics move toward restricting treatment to more severely mentally ill patients (those with psychotic and bipolar illness) and primary care doctors have better resources to manage depressive illness, and with guidelines now recommending screening of depression in primary care, ${ }^{3,4}$ the treatment of MDD increasingly falls upon primary care physicians.

Evidence-based management approaches to depression that increase chances of remission and response in primary care clearly exist. ${ }^{61-63}$ Still, this burden is not light. In this large, broadly inclusive sample, the risk factors for chronic and recurrent depressive illnessincluding a long period of depressive illness, a history of depressive episodes, suicidal ideation, and psychiatric comorbidity - were frequently present. This finding indicates a clear risk for treatment resistance and highlights the need for aggressive management strategies in both settings.

To read or post commentaries in response to this article, see it online at http://www.annfammed.org/cgi/content/full/5/2/126.

Key words: Primary care; depression; suicide; psychiatric comorbidity

Submitted March 6, 2006; submitted, revised, July 26, 2006; accepted August 14, 2006.

Funding support: This project has been funded by grants from the National Institute of Mental Health, under contract N01MH90003 to UT Southwestern Medical Center at Dallas (Principal investigator, A. J. Rush). Dr. Gaynes was supported in part by an National Institute of Mental Health K23 Career Development Award (MH01951-03).

Disclaimer: The content of this publication does not necessarily reflect the views or policies of the Department of Health and Human Services, nor does mention of trade names, commercial products, or organizations imply endorsement by the US Government.

Acknowledgments: We would like to thank the STAR*D investigators for all the help in making this large and complex multicenter study possible and for generating the data for this report. We would also like to acknowledge the editorial support of Jon Kilner, MS, MA, and the secretarial support of Fast Word Information Processing Inc (Dallas, Tex).

Conflicts of interest: Bradley Gaynes has served as a consultant for Pfizer and Wyeth-Ayerst and has received a speaker honorarium from 
GlaxoSmithKline. Madbukar Trivedi has received research funds from Abbott, Akzo (Organon), Bayer, Bristol-Myers Squibb, Eli Lilly, Forest, GlaxoSmithKline, Janssen, Johnson \& Johnson, Mead Johnson, ParkeDavis, Pfizer, Pharmacia \& Upjohn, Solvay, and Wyeth-Ayerst, and has served as a speaker or consultant for Bristol-Myers Squibb, Forest, Janssen, Eli Lilly, Organon, Pharmacia \& Upjohn, Solvay, Wyeth-Ayerst, Pfizer, and Cyberonics. Diane Warden has shares in Pfizer. Linda Nicholas has received speaker honoraria from Astra-Zeneca, Bristol-Myers Squibb, Eli Lilly, and GlaxoSmithKline, and research funds from Bristol-Myers Squibb, Forest, Pfizer, and Parke-Davis. Maurizio Fava has received research support from Abbott, Lichtwer Pharma GmBH, Lorex; and honoraria from Bayer AG, Compellis, Janssen, Knoll, Lundbeck, Dov, Biovail, BrainCells, Inc, Cypress, Fabre-Krame, Grunenthal GmBH, MedAvante, Sepracor, and Somerset, and research support and honoraria from Aspect Medical Systems, Astra-Zeneca, Bristol-Myers Squibb, Cephalon, Eli Lilly, Forest, GlaxoSmithKline, JEJ Pharmaceuticals, Novartis, Organon, Pharmavite, Pfizer, Roche, Sanofi/Synthelabo, Solvay, and Wyeth-Ayerst.

\section{References}

1. Stafford RS, MacDonald EA, Finkelstein SN. National Patterns of Medication Treatment for Depression, 1987 to 2001. Prim Care Companion J Clin Psychiatry. 2001;3(6):232-235.

2. Middleton N, Gunnell D, Whitley E, Dorling D, Frankel S. Secular trends in antidepressant prescribing in the UK, 1975-1998. J Public Health Med. 2001;23(4):262-267.

3. Screening for depression: recommendations and rationale. Ann Intern Med. 2002;136(10):760-764.

4. National Institute for Clinical Excellence (NICE). Depression: management of depression in primary and secondary care. Available at: http://www.nice.org.uk/pdf/CG023quickrefguide.pdf. Accessed: 16 January 2006.

5. Tylee $A$, Jones R. Managing depression in primary care. BMJ. 2005;330(7495):800-801.

6. Gunnell D, Saperia J, Ashby D. Selective serotonin reuptake inhibitors (SSRIs) and suicide in adults: meta-analysis of drug company data from placebo controlled, randomised controlled trials submitted to the MHRA's safety review. BMJ. 2005;330(7488):385.

7. Wessely S, Kerwin R. Suicide risk and the SSRIs. JAMA. 2004;292(3):379-381.

8. Williamson PS, Yates WR. The initial presentation of depression in family practice and psychiatric outpatients. Gen Hosp Psychiatry. 1989;11(3):188-193; discussion 216-121.

9. Schwenk TL, Coyne JC, Fechner-Bates S. Differences between detected and undetected patients in primary care and depressed psychiatric patients. Gen Hosp Psychiatry. 1996;18(6):407-415.

10. Cooper-Patrick L, Crum RM, Ford DE. Characteristics of patients with major depression who received care in general medical and specialty mental health settings. Med Care. 1994;32(1):15-24.

11. Simon GE, VonKorff M. Recognition, management, and outcomes of depression in primary care. Arch Fam Med. 1995;4(2):99-105.

12. Simon GE, Lin EH, Katon W, et al. Outcomes of "inadequate" antidepressant treatment. J Gen Intern Med. 1995;10(12):663-670.

13. Suh T, Gallo JJ. Symptom profiles of depression among general medical service users compared with specialty mental health service users. Psychol Med. 1997;27(5):1051-1063.

14. Kroenke K, Price RK. Symptoms in the community. Prevalence, classification, and psychiatric comorbidity. Arch Intern Med. 1993;153(21):2474-2480.

15. Ohayon MM, Schatzberg AF. Prevalence of depressive episodes with psychotic features in the general population. Am J Psychiatry 2002;159(11):1855-1861.
16. Gaynes BN, Rush AJ, Trivedi M, et al. A direct comparison of presenting characteristics of depressed outpatients from primary vs. specialty care settings: preliminary findings from the STAR* $D$ clinical trial. Gen Hosp Psychiatry. 2005;27(2):87-96.

17. Rush AJ, Fava M, Wisniewski SR, et al. Sequenced treatment alternatives to relieve depression (STAR*D): rationale and design. Control Clin Trials. 2004;25(1):119-142.

18. Gaynes B, Davis L, Rush A, et al. The Aims and Design of the Sequenced Treatment Alternatives to Relieve Depression (STAR*D) Study. Primary Psychiatry. 2005;12(2):36-41.

19. Hamilton M. A rating scale for depression. J Neurol Neurosurg Psychiatry. 1960;23:56-62.

20. Hamilton M. Development of a rating scale for primary depressive illness. Br J Soc Clin Psychol. 1967;6(4):278-296.

21. Linn BS, Linn MW, Gurel L. Cumulative illness rating scale. J Am Geriatr Soc. 1968;16(5):622-626.

22. Zimmerman M, Mattia JI. A self-report scale to help make psychiatric diagnoses: the Psychiatric Diagnostic Screening Questionnaire. Arch Gen Psychiatry. 2001;58(8):787-794.

23. Zimmerman M, Mattia Jl. The Psychiatric Diagnostic Screening Questionnaire: development, reliability and validity. Compr Psychiatry. 2001;42(3):175-189.

24. First M, Spitzer R, Gibbon M, Williams J. Structured Clinical Interview for DSM-IV Axis I Disorders, Clinician Version (SCID-CV). Washington, DC: American Psychiatric Press, Inc; 1996.

25. Simon GE, Revicki D, VonKorff M. Telephone assessment of depression severity. J Psychiatr Res. 1993;27(3):247-252.

26. Rush AJ, Gullion CM, Basco MR, Jarrett RB, Trivedi MH. The Inventory of Depressive Symptomatology (IDS): psychometric properties. Psychol Med. 1996;26(3):477-486.

27. Trivedi MH, Rush AJ, Ibrahim HM, et al. The Inventory of Depressive Symptomatology, Clinician Rating (IDS-C) and Self-Report (IDS-SR), and the Quick Inventory of Depressive Symptomatology, Clinician Rating (QIDS-C) and Self-Report (QIDS-SR) in public sector patients with mood disorders: a psychometric evaluation. Psychol Med. 2004;34(1):73-82.

28. Kobak KA, Greist JH, Jefferson JW, Mundt JC, Katzelnick DJ. Computerized assessment of depression and anxiety over the telephone using interactive voice response. MD Comput. 1999;16(3):64-68.

29. Sugar CA, Sturm R, Lee TT, et al. Empirically defined health states for depression from the SF-12. Health Serv Res. 1998;33(4 pt 1):911-928.

30. Endicott J, Nee J, Harrison W, Blumenthal R. Quality of Life Enjoyment and Satisfaction Questionnaire: a new measure. Psychopharmacol Bull. 1993;29(2):321-326.

31. Mundt JC, Marks IM, Shear MK, Greist JH. The Work and Social Adjustment Scale: a simple measure of impairment in functioning. Br J Psychiatry. 2002;180:461-464.

32. Schulberg HC, Madonia MJ, Block MR, et al. Major depression in primary care practice. Clinical characteristics and treatment implications. Psychosomatics. 1995;36:129-137.

33. Katzelnick DJ, Simon GE, Pearson SD, et al. Randomized trial of a depression management program in high utilizers of medical care. Arch Fam Med. 2000;9(2):345-351.

34. Hunkeler EM, Meresman JF, Hargreaves WA, et al. Efficacy of nurse telehealth care and peer support in augmenting treatment of depression in primary care. Arch Fam Med. 2000;9(4):700-708.

35. Ioannidis JP. Why most published research findings are false. PLoS Med. 2005;2(8):e124.

36. Ioannidis JP. Contradicted and initially stronger effects in highly cited clinical research. JAMA. 2005;294(8):218-228.

37. Sleath B, Shih YC. Sociological influences on antidepressant prescribing. Soc Sci Med. 2003;56(6):1335-1344. 
38. Olfson M, Marcus SC, Druss B, et al. National trends in the outpatient treatment of depression. JAMA. 2002;287(2):203-209.

39. Zimmerman M, Chelminski I, Posternak MA. Generalizability of antidepressant efficacy trials: differences between depressed psychiatric outpatients who would or would not qualify for an efficacy trial. Am J Psychiatry. 2005;162(7):1370-1372.

40. Posternak MA, Zimmerman M, Keitner GI, Miller IW. A reevaluation of the exclusion criteria used in antidepressant efficacy trials. Am J Psychiatry. 2002;159(2):191-200.

41. Wells KB. Treatment research at the crossroads: the scientific interface of clinical trials and effectiveness research. Am J Psychiatry. 1999;156(1):5-10.

42. Simon GE, Von Korff M, Rutter CM, Peterson DA. Treatment process and outcomes for managed care patients receiving new antidepressant prescriptions from psychiatrists and primary care physicians. Arch Gen Psychiatry. 2001;58(4):395-401.

43. Gaynes BN, West SL, Ford CA, et al. Screening for suicide risk in adults: a summary of the evidence for the U.S. Preventive Services Task Force. Ann Intern Med. 2004;140(10):822-835.

44. Regier DA, Rae DS, Narrow WE, Kaelber CT, Schatzberg AF. Prevalence of anxiety disorders and their comorbidity with mood and addictive disorders. Br J Psychiatry Suppl. 1998(34):24-28.

45. Yerevanian BI, Koek RJ, Ramdev S. Anxiety disorders comorbidity in mood disorder subgroups: data from a mood disorders clinic. $J$ Affect Disord. 2001;67(1-3):167-173.

46. Brown TA, Campbell LA, Lehman CL, Grisham JR, Mancill RB. Current and lifetime comorbidity of the DSM-IV anxiety and mood disorders in a large clinical sample. J Abnorm Psychol. 2001;110(4): 585-599.

47. Gaynes BN, Magruder KM, Burns BJ, et al. Does a coexisting anxiety disorder predict persistence of depressive illness in primary care patients with major depression? Gen Hosp Psychiatry. 1999;21(3):1 58-167.

48. Stein MB, Kirk P, Prabhu V, Grott M, Terepa M. Mixed anxietydepression in a primary-care clinic. J Affect Disord. 1995;34(2):79-84

49. Rush AJ, Zimmerman M, Wisniewski SR, et al. Comorbid psychiatric disorders in depressed outpatients: demographic and clinical features. J Affect Disord. 2005;87(1):43-55.

50. Zimmerman M, Chelminski I. Screening for anxiety disorders in depressed patients. J Psychiatr Res. 2006;40(3):267-272.
51. Zimmerman M, Sheeran T. Screening for principal versus comorbid conditions in psychiatric outpatients with the Psychiatric Diagnostic Screening Questionnaire. Psychol Assess. 2003;15(1):110-114

52. Ormel J, Koeter MW, van den Brink W, van de Willige G. Recognition, management, and course of anxiety and depression in general practice. Arch Gen Psychiatry. 1991;48(8):700-706.

53. Coyne JC, Schwenk TL, Fechner-Bates S. Nondetection of depression by primary care physicians reconsidered. Gen Hosp Psychiatry. 1995;17(1):3-12.

54. Wells KB, Hays RD, Burnam MA, et al. Detection of depressive disorder for patients receiving prepaid or fee-for-service care. Results from the Medical Outcomes Study. JAMA. 1989;262(23):3298-3302.

55. US Department of Health and Human Services. Healthy People 2010: Understanding and Improving Health. 2nd ed. Washington, DC: US Government Printing Office; 2000.

56. Kessler RC, Berglund P, Demler O, et al. The epidemiology of major depressive disorder: results from the National Comorbidity Survey Replication (NCS-R). JAMA. 2003;289(23):3095-3105.

57. Olfson M, Marcus SC, Tedeschi M, Wan GJ. Continuity of antidepressant treatment for adults with depression in the United States. Am J Psychiatry. 2006;163(1):101-108.

58. Norman GR, Sloan JA, Wyrwich KW. Interpretation of changes in health-related quality of life: the remarkable universality of half a standard deviation. Med Care. 2003;41(5):582-592.

59. McHorney CA, Tarlov AR. Individual-patient monitoring in clinical practice: are available health status surveys adequate? Qual Life Res. 1995;4(4):293-307.

60. Trivedi MH, Rush AJ, Wisniewski SR, et al. Evaluation of outcomes with citalopram for depression using measurement-based care in STAR*D: implications for clinical practice. Am J Psychiatry. 2006;163(1):28-40

61. Neumeyer-Gromen A, Lampert T, Stark K, Kallischnigg G. Disease management programs for depression: a systematic review and meta-analysis of randomized controlled trials. Med Care. 2004;42(12)1211-1221.

62. Oxman TE, Dietrich AJ, Schulberg HC. Evidence-based models of integrated management of depression in primary care. Psychiatr Clin North Am. 2005:28(4):1061-1077.

63. Grypma L, Haverkamp R, Little S, Unutzer J. Taking an evidencebased model of depression care from research to practice: making lemonade out of depression. Gen Hosp Psychiatry. 2006;28(2):101-107. 